\title{
Genetic Diversity among Flue-cured Tobacco Cultivars Based on RAPD and AFLP Markers
}

\author{
Han Yao Zhang ${ }^{1}$, Xiao Zhen Liu ${ }^{1}$, Chuan Sheng $\mathrm{He}^{2}$ and Yu Ming Yang ${ }^{1}$ \\ ${ }^{1}$ Biotechnology Laboratory; Southwest Forestry College; White Dragon Temple; Kunming, Yunnan Province- \\ 650224; People's Republic of China. ${ }^{2}$ The South Center of Tobacco Breeding Research of China; Yuxi, Yunnan- \\ 653100; People's Republic of China
}

\begin{abstract}
The aim of this work was to study the genetic diversity among flue-cured tobacco cultivars. RAPD and AFLP analyses were used to assess the genetic similarity among selected accessions of flue-cured tobacco. Seventy eight RAPD and 154 AFLP polymorphic bands were obtained and used to assess the genetic diversity among 28 tobacco accessions. The cultivar relationships were estimated through the cluster analysis (UPGMA) based on RAPD data and AFLP data. The accessions were grouped into three major clusters and these shared common ancestry clustered together.
\end{abstract}

Key words: Flue-cured tobacco, RAPD, AFLP, genetic diversity, DNA polymorphism

\section{INTRODUCTION}

The flue-cured tobacco (Nicotiana tabacum L.) is one of the most important types for the tobacco production in the world. Undoubtedly, the study of the genetic diversity of flue-cured tobacco cultivars is important not only for the germplasm conservation but also in parental choice for breeding purposes. The RAPD (random amplified polymorphic DNA) and AFLP (amplified fragment length polymorphism) are genetic fingerprinting techniques suitable for the genetic evaluation of flue-cured tobacco. The techniques have been successfully used to genetically analyze many different plant species (Crochemore et al., 2003; Diniz et al., 2005; Ni et al., 2006 and Yang et al., 2006).

In this work, the RAPD and AFLP procedures were used to assess the amount of polymorphisms detected among the flue-cured tobacco cultivars and to estimate the relationships.

\section{MATERIALS AND METHODS}

\section{Plant Materials}

The seeds of the flue-cured tobacco were obtained from the germplasm collection of the South Center Tobacco Breeding Research of China in Yunnan province, southwest of China. The collection was consisted of 298 cultivars and breeding lines from different places. On the basis of results from the field trials conducted at Yuxi, Yunnan, from 1994 to 1996 (Lei et al., 1997), 28 accessions with desirable agronomic characteristics, such as large leaf size, high leaf yields, low nicotine contains, or resistance to various diseases or insects, were selected for evaluation in this study. These

\footnotetext{
* Author for correspondence
} 
accessions represented the genotypes likely to be used in future flue-cured tobacco breeding efforts in south China. The name and origin of the cultivar were showed in the Table 1.

The seeds were planted in the pots and grown in the greenhouse at 28 to $32{ }^{\circ} \mathrm{C}$. Twenty days after the germination, the shoots were harvested from 40 seedlings of each accession. The DNA was extracted from the shoots by the CTAB method (De Riek et al., 2001).

\section{RAPD analysis}

The amplification was performed in $20 \mu \mathrm{L}$ solution containing $2 \mu \mathrm{L}$ of the $10 \times$ buffer, and $100 \mathrm{mM}$ each of dNTPs, $0.4 \mathrm{mM}$ primer, $25 \mathrm{ng}$ genomic DNA, and 1 unit of Taq polymerase. The reaction mixture was overlaid with $40 \mu \mathrm{L}$ mineral oil. The amplifications were carried out using a 2400 Perkin-Elmer (Perkin Elmer, USA) thermal cycler programmed for 40 cycles as follows: $30 \mathrm{~s}$ at $94^{\circ} \mathrm{C}, 30 \mathrm{~s}$ at $36^{\circ} \mathrm{C}, 1.5 \mathrm{~min}$ at $72{ }^{\circ} \mathrm{C}$, with an initial melting of $6 \mathrm{~min}$ at $94{ }^{\circ} \mathrm{C}$, and a final extension of $6 \mathrm{~min}$ at $72{ }^{\circ} \mathrm{C}$. The amplification products were analyzed by the electrophoresis in a $1.5 \%$ agarose gel with $1 \times$ TAE buffer $(0.004 \mathrm{M}$ Tris-acetate and 0.002 M EDTA).

Table 1- Flue-cured tobacco cultivars with pedigree and origin used in RAPD and AFLP analysis.

\begin{tabular}{|c|c|c|c|}
\hline Number & Cultivar & Pedigree & Origin \\
\hline 1 & Changbohuang & Unknown & Henan(CHN) \\
\hline 2 & $\mathrm{NC} 82$ & $6129 \times$ Coker 319 & USA \\
\hline 3 & 581 & Chujingyan & Yunnan $(\mathrm{CHN})$ \\
\hline 4 & Yunyan 3 & Zhaojie 8 dui $\times$ Coker347 & Yunnan(CHN) \\
\hline 5 & Jingtai33 & Unknown & Shangxi(CHN) \\
\hline 6 & Yunyan 86 & Yunyan $2 \times \mathrm{K} 326$ & Yunnan(CHN) \\
\hline 7 & Yunyan 76 & Speight G-28×K326 & Yunnan(CHN) \\
\hline 8 & Jingyehuang & Changbohuang & $\operatorname{Henan}(\mathrm{CHN})$ \\
\hline 9 & $82-3041$ & Speight G-28×Burley599 & Henan(CHN) \\
\hline 10 & Zhongyan 86 & Speight G-28×Jingyehuang & Henan (CHN) \\
\hline 11 & Jiyan 5 & Jingyehuang $\times$ Coker86 & Jiling(CHN) \\
\hline 12 & CV87 & $($ CV $58 \times$ Speight G-28 $) \times[$ CV58 $\times($ Speight G- $28 \times$ NC 82$)$ F1] & Henan $(\mathrm{CHN})$ \\
\hline 13 & $77809-12$ & ( Lingi $1 \times$ Virginia 115 ) F6 & Yunnan(CHN) \\
\hline 14 & Qingsheng 2 & Jingyehuang & $\operatorname{Henan}(\mathrm{CHN})$ \\
\hline 15 & Yunyan 84 & Yunyan $2 \times \mathrm{K} 326$ & Yunnan $(\mathrm{CHN})$ \\
\hline 16 & Chunjingyan & Gold Dollar & Yunnan(CHN) \\
\hline 17 & Jingxing 6007 & Jingxing & Henan $(\mathrm{CHN})$ \\
\hline 18 & RG11 & NC50×K399 & USA \\
\hline 19 & Zhongyan 14 & Jingxing6007×Speight G-28 & $\operatorname{Henan}(\mathrm{CHN})$ \\
\hline 20 & Yunyan 1 & Gold Dollar & Yunnan $(\mathrm{CHN})$ \\
\hline 21 & K394 & Speight G-28×McNair944 & USA \\
\hline 22 & Xiaohuangjing 1025 & Xiaohuangjing & Shangdong $(\mathrm{CHN})$ \\
\hline 23 & 8813 & Unknown & Shichuan (CHN) \\
\hline 24 & Yunyan 2 & Red Flowers Gold Dollar×Speight G-28 & Yunnan(CHN) \\
\hline 25 & CV85 & $($ CV58×Speight G-28 ) $\times[$ CV58× ( Speight G-28×NC82 ) F1] & Henan $(\mathrm{CHN})$ \\
\hline 26 & CV73 & ( CV58×Speight G-28) $\times[$ CV58 $\times($ Speight G-28×NC82 ) F1] & Henan $(\mathrm{CHN})$ \\
\hline 27 & Oxford 26 & TI $448 \mathrm{~A} \times 400$ & USA \\
\hline 28 & K149 & $\begin{array}{l}\text { [Speight G-28 } \times \text { Coker254] } \times(\text { CB139 } \times \text { F-105 }) \times(\text { Speight G- } \\
28 \times \text { Coker254 ) } \times \text { McN399 }\end{array}$ & USA \\
\hline
\end{tabular}

\section{AFLP analysis}

The AFLP analysis was performed following the manufacturer's protocol (Life Technologies). The DNA was digested simultaneously with restriction enzymes EcoRI and MseI. The selective amplifications were performed using the primer pairs listed in Table 2. The restricted genomic DNA fragments were ligated to EcoRI and MseI adapters. The primers within set EcoRI included the sequence 5'- GAC TGC GTA CCA ATT C; primers of the MseI set had the sequence 5'-GAT GAG TCC TGA GTA A. The pre and the selective amplifications were performed in a 2400 PerkinElmer Thermocycler. An equal volume $(2 \mu \mathrm{L})$ of loading dye $(95 \% \mathrm{v} / \mathrm{v}$ formamide and $0.08 \% \mathrm{w} / \mathrm{v}$ bromophenol blue, $20 \mathrm{mM}$ EDTA) was added to each sample, which was then denatured at $95^{\circ} \mathrm{C}$ for $3 \mathrm{~min}$ and placed on the ice for $2 \mathrm{~min}$ before loading. The amplification products were analyzed by the electrophoresis in a $6.5 \%$ polyacrylamide 
gel. The electrophoresis parameters were set to $1500 \mathrm{~V}, 40.0 \mathrm{~mA}, 40.0 \mathrm{~W}, 50^{\circ} \mathrm{C}$ and the run time was set to $2.0 \mathrm{~h}$. Separated AFLP products were visualized using silver staining as described in the Promega Silver Staining kit and gel images were saved as TIF files for analysis.

\section{Data analysis}

Each accession was scored 1 for the presence or 0 for the absence of each polymorphic band. The bands present in all accessions were not scored.

Only bright, clearly distinguishable bands were used in the genetic analysis. All the statistical analyses were performed by NTSYS-pc, Version 1.8. Similarity matrices (data not shown) were constructed from the binary data with Jaccard's coefficients (Jaccard, 1908). The dendrograms were generated with the unweighted pair-group method, arithmetic average (UPGMA) algorithm as described by Sneath and Sokal (1973).

\section{RESULTS AND DISCUSSION}

From the 200 primers used in RAPD analysis, 63 $(31.5 \%)$ produced the amplification products that were too faint to score or could not be consistently reproduced, and $124 \quad(62 \%)$ produced monomorphic banding patterns. Only $13(6.5 \%)$ out of 200 primers were scored. A total of 125 bands were scored from the comparison of amplifications with 13 primers of DNAs from 28 flue-cured tobacco cultivars, with an average of 9.6 bands scored per primer (Table 2.). The polymorphic bands were $78(62.4 \%)$, and one primer detected a mean of 6 polymorphic bands per reaction.

Fourteen selective AFLP primers were screened against all 28 accessions. Four primer pairs were not included in the final analysis because either the amplification profile was consistently too faint to score accurately (AAC/CGC) or only monomorphic amplification products were produced (AAC/CTG, ACT/CTC, ACT/CTG). The ten informative primer pairs used in the final analysis were listed in Table 2. A total of 154 fragments were analyzed using the ten pairs of primers. Five hundred and sixty-one fragments were scored in the assay performed by using the ten pairs, with an average of 56.1 fragments per pair of primers used. One hundred and fifty-four fragments were polymorphic, with an average of 15.4 per reaction, with $27.45 \%$ polymorphism.

Table 2- DNA fragment polymorphism in flue-cured cultivars after RAPD and AFLP analysis.

\begin{tabular}{|c|c|c|c|c|c|c|c|}
\hline $\begin{array}{l}\text { RAPD } \\
\text { Primer }\end{array}$ & $\begin{array}{r}\text { Total } \\
\text { bands }\end{array}$ & $\begin{array}{c}\text { Polymorphic } \\
\text { bands }\end{array}$ & $\begin{array}{c}\text { Polymorphism } \\
\%\end{array}$ & $\begin{array}{c}\text { AFLP } \\
\text { Primer pair }\end{array}$ & $\begin{array}{l}\text { Total } \\
\text { bands }\end{array}$ & $\begin{array}{c}\text { Polymorphic } \\
\text { bands }\end{array}$ & $\begin{array}{c}\text { Polymorphism } \\
\%\end{array}$ \\
\hline OPA 03 & 3 & 2 & & $\mathrm{ACC} / \mathrm{CAG}$ & 52 & 12 & \\
\hline OPA 04 & 10 & 4 & & ACC/CTG & 76 & 26 & \\
\hline OPA 07 & 13 & 9 & & ACC/CAT & 66 & 25 & \\
\hline OPB 01 & 10 & 6 & & $\mathrm{ACC} / \mathrm{CAA}$ & 39 & 15 & \\
\hline OPB 13 & 6 & 4 & & ACC/CTT & 49 & 3 & \\
\hline OPC 01 & 7 & 4 & & AAC/CAT & 64 & 11 & \\
\hline OPD 05 & 8 & 5 & & $\mathrm{AAC} / \mathrm{CAG}$ & 38 & 1 & \\
\hline OPD 14 & 8 & 5 & & AAG/CAA & 47 & 3 & \\
\hline OPK 01 & 6 & 5 & & $\mathrm{AAG} / \mathrm{CAG}$ & 81 & 26 & \\
\hline OPL 03 & 14 & 9 & & AAG/CTT & 53 & 32 & \\
\hline OPL 09 & 14 & 8 & & & & & \\
\hline OPW 05 & 11 & 10 & & & & & \\
\hline OPY 10 & 15 & 7 & & & & & \\
\hline Total & 125 & 78 & $62.4 \%$ & & 561 & 154 & $27.45 \%$ \\
\hline Average & 9.6 & 6 & & & 56.1 & 15.4 & \\
\hline
\end{tabular}

Results from cluster analyses using RAPD or AFLP data indicated that these two marker techniques provided similar, but not identical information (data not shown). For example, Zhongyan 86 was the offspring of both Speight G28 and Jingyehuang, in the dendrogram based on RAPD data, it was clustered with the progenies of Jingyehuang; it was grouped with the progenies of Speight G-28, in the dendrogram based on AFLP data. This observation could be related to the larger number of AFLP bands used in the analyses compared with the number of RAPD bands used. The RAPD and AFLP data were combined to generate a dendrogram incorporating both types of the DNA marker data, the relationships among the accessions analyzed are shown in Fig. 1. The RAPD and AFLP based Jaccard's similarity coefficients ranged from 0.13 to 0.88 . The 
accessions were grouped into three major clusters. Group I included $17.86 \%$ of the accessions; group II included $64.29 \%$ of the accessions; group III included $17.86 \%$ of the accessions.

The dendrogram did not indicate any clear pattern of division among the flue-cured tobacco accessions based on the geographic origin, as seen in some other crops (Paul et al., 1997; Spooner et al., 1996). However, those accessions that shared common ancestry clustered together. For example, the cultivars bred by Speight G-28 such as 823041, K149, K394, Zhongyan 14, CV73, CV85 and CV87 (Table 1) were clustered together in Group II; Jiyan 5 and Qingsheng 2 were the offsprings of the Jingyehuang, Jingyehuang was bred by Changbohuang (Table 1), they were all clustered with Jingyehuang in Group II; Yunyan 2, chunjingyan and Yunyan1 were bred by Gold Dollar (Table 1), they were clustered together in Group I; and one of the crossing parents of Yunyan 76, Yunyan 84 and Yunyan 86 was K326 (Table 1), they were also clustered together in GroupII.

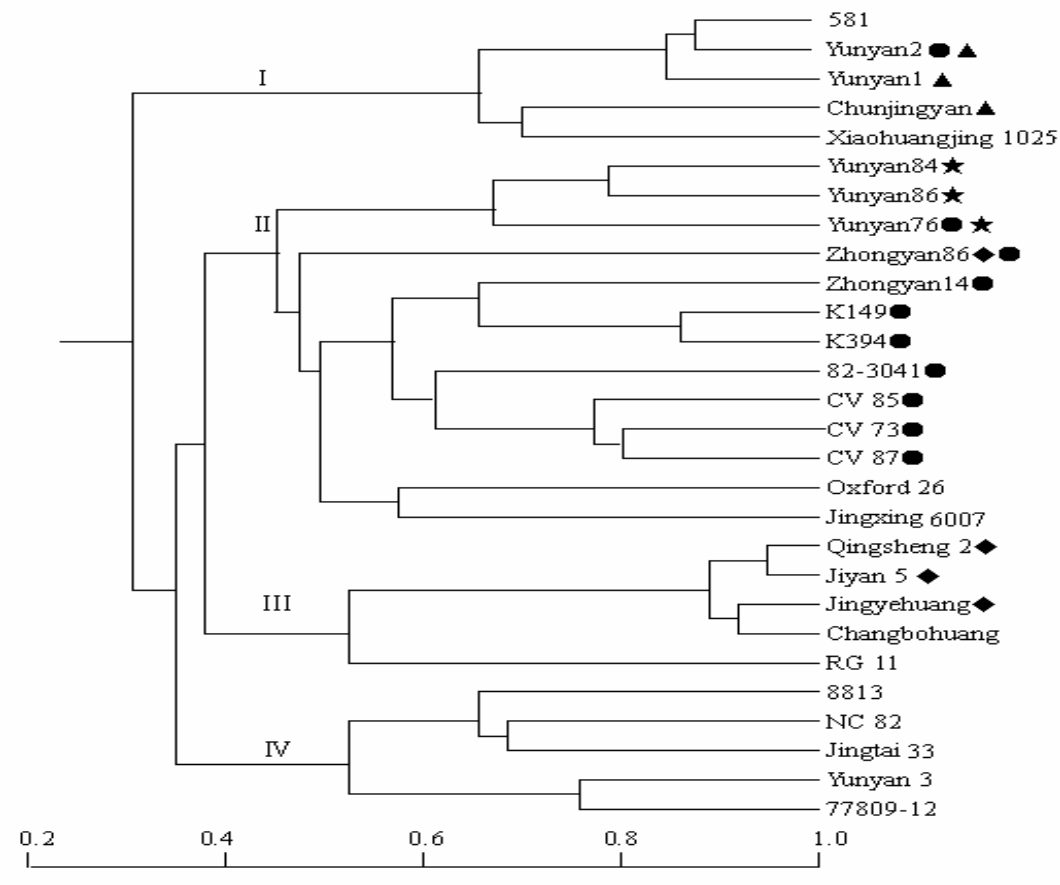

Figure 1 - Dendrogram of the 24 flue-cured tobacco cultivars from cluster analysis (UPGMA) of the genetic distances, on the basis of RAPD and AFLP data. Symbols indicate ancestry of origin: $\bullet=$ Jingyehuang. $\bullet=$ Speight G-28. $\boldsymbol{\Delta}=$ Gold Dollar. $\star=$ K326.

\section{ACKNOWLEDGEMENTS}

The experiments in this study were carried out at the South Center Tobacco Breeding Research of China, the expenses were provided by Yunnan Tobacco Company, and the Natural Science Foundation of Yunnan (Grant No. 2007 C 216 M).

\section{REFERENCES}

Crochemore, M. L.; Molinari, H. B. C. and Vieira, L. G. E. (2003), Genetic diversity in passion fruit (Passiflora spp.) evaluated by RAPD markers. Braz. arch. biol. technol., 46:521-527.

De Riek, J.; Calsyn, E.; Everaert, I.; Van Bockstaele, E. and De Loose, M. (2001), AFLP based alternatives for the assessment of distinctness, uniformity and stability of sugar beet varieties. Theor. Appl. Genet., 103:1254-1265. 
Diniz, L. E. C.; Ruas C. F.; Carvalho V. P.; Torres F. M.; Ruas E. A.; Santos M. O.; Sera T. and Ruas P. M. (2005), Genetic diversity among forty coffee varieties assessed by RAPD markers associated with restriction digestion. Braz. arch. biol. technol., 48:511-521.

Lei, Y. H.; Xu, M. L. and Huang, X. Y. (1997), Tobacco collection in the Yunnan province. Science and Technology publishing company of Yunnan pp. 21-70.

Jaccard, P. (1908), Nouvelles recherches sur la distribution florale. Bull. Soc. Vaud. Sci. Nat., 44:223-270.

Ni, X. W.; Huang, Y. L.; Wu, L.; Zhou, R. C.; Deng, S. L.; Wu, D. R.; Wang, B. S.; Su, G. H.; Tang, T.; Shi, S. H. (2006), Genetic diversity of the endangered Chinese endemic herb Primulina tabacum (Gesneriaceae) revealed by amplified fragment length polymorphism (AFLP). Genetica., 127:177183.

Paul, S.; Wachira, F. N.; Powell, W. and Waugh R. (1997), Diversity and genetic differentiation among populations of Indian and Kenyan tea (Camellia sinensis (L.) O. Kuntze) revealed by AFLP markers. Theor. Appl. Genet., 94:255-263.

Sneath, P. H. A. and Sokal, R. R. (1973), Numerical taxonomy. Freeman, San Francisco, Calif. pp. 573.

Spooner, D. M.; Tivang, J.; Neinhuis, J.; Miller, J. T.; Douches, D. S. and Contreras-m A. (1996), Comparison of four molecular markers in measuring relationships among wild potato relatives Solanum section etuberosum (subgenus Potatoe). Theor. Appl. Genet., 92:532-540.

Yang, S. Y.; Pang, W.; Ash, G..; Harper, J.; Carling, J.; Wenzl, P.; Huttner, E.; Zong, X. X.; Kilian, A. (2006), Low level of genetic diversity in cultivated Pigeonpea compared to its wild relatives is revealed by diversity arrays technology. Theor. Appl. Genet., 113:585-595.
Received: November 30, 2005; Revised: October 10, 2007; Accepted: February 01, 2008. 
PÁGINA

EM

BRANCO 